\title{
LOS "ECOS DE LA ADELITA": LA OBRA DE ALAN KNIGHT SOBRE MÉXICO
}

VÍCTOR M. GONZÁLEZ ESPARZA

Departamento de Historia/UAA

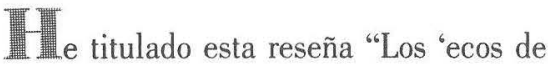
la Adelita': la obra de Alan Knight sobre México" como paráfrasis o como un modesto reconocimiento a la obra de otro historiador inglés, Eric Hobsbawm, quien en su libro "Los Ecos de la Marsellesa" realizó una crítica historiográfica del revisionismo en uso rescatando así el significado liberador de la Revolución francesa. Sirva pues esta pequeña referencia para contextualizar entre nosotros a otro magnífico historiador inglés.

Cuando me invitó Yolanda Padilla a participar en este evento, antes de saber incluso sobre las instituciones que colaboran para su realización (no porque me desagrade alguna sino, por el contrario, porque me complace que se hayan puesto de acuerdo para llevarlo a cabo), sin pensarlo mucho, accedí inmediatamente. Contribuir a la difusión de la obra de Alan Knight me pareció y me sigue pareciendo, más allá de la cortesía aguascalentense, un ejercicio indispensable dentro de la historiografía sobre la Revolución Mexicana. Porque, como trataré de mostrarlo en las siguientes líneas, la obra de Knight (no sólo su libro "monumental" -tanto por el número de páginas escritas como por ser una obra que nos restablece la memoria según una vieja distinción clásica-, sino también la veintena de excelentes ensayos de los que sólo se conoce una cuarta parte en español) reinstala algunos equilibrios que desafortunadamente con la vulgarización del "revisionismo" se perdieron en nuestra visión sobre la revolución. Gracias pues a los organizadores por permitirnos reflexionar junto con el profesor Knight.

La historiografía de este siglo sobre las revoluciones, a riesgo de simplificar dada la abundancia de textos, puede abordarse a través de tres generaciones. La primera, bajo las contradicciones inte- 
lectuales que surgieron de la Revolución Rusa, trató de aprehender el fenómeno revolucionario por medio de una concepción estática e incluso biológica de los procesos, por lo que incluso se llegó a hablar de una "historia natural de las revoluciones" con etapas y generalizaciones aplicables a cualquier tiempo y lugar; así, por ejemplo, la desafección de los intelectuales con el antiguo régimen, las reformas del estado en agonía, la crisis política, la oposición revolucionaria, etc., se plantearon como patrones por los cuales las revoluciones transcurrían.

La segunda generación, más cerca de las revoluciones china y cubana, así como de las revoluciones anticolonialistas, se orientó finalmente hacia una teoría general de la violencia. La frustración de las expectativas, el desequilibrio institucional provocado por la modernización (vgr. Samuel P. Huntington) y la capacidad de los actores para movilizar recursos en el ejercicio de la violencia (vgr. Charles Tilly), fueron algunas de las preocupaciones de esta perspectiva.

Sin embargo, una veta importante de esta generación se identificaría también con lo que se ha dado en llamar "teoría estructural de la revolución", es decir, un análisis de largo plazo de temas tales como la formación de los estados nacionales, las rebeliones campesinas y la estructura agraria (Eric Wolf), el papel de las ideologías en el proceso revolucionario, el análisis de la autonomía del Estado frente a interpretaciones reduccionistas (Theda Skocpol), en fin, la diferenciada relación entre campesinos y latifundistas frente a procesos modernizadores como eje explicativo (vgr. Barrington Moore).

Como una reacción a esta interpretación "estructural", o quizá a algunas caricaturas de ésta, se desarrollaría la tercera generación de historiadores a partir de una corriente mejor conocida como "revisionismo." Podría decirse que esta generación es producto de un desencanto (1968), alimentado por el anunciado "fin de la historia" y la caída del muro de Berlín y sus secuelas. Así como la visión estructural se nutrió del marxismo, el revisionismo se nutrió de viejas críticas a las revoluciones (vgr. del escepticismo de Burke y Toçueville, en el mejor de los casos -como el de Francois Furet-, al claro conservadurismo de Taine y Cochin), por lo que el revisionismo parece un tanto difícil de englobar, toda vez que se confunde con nuestro "posmoderno" fin de siglo. Sin embargo, como bien lo señalara el Prof. Knight en uno de sus brillantes ensayos ("Viewpoint: Revisionism and Revolutions: Mexico Compared to England and France" en Past and Present, Núm.132, Feb. 1992, pp.159-199) algunos de los temas privilegiados por los revisionistas han si- 
do: la centralización del estado como negativa, el cuestionamiento de lo popular de la revolución, la continuidad sobre la ruptura, la reivindicación del antiguo régimen y de personajes e historiadores contrarevolucionarios, etc.

Para el caso de México, tres generaciones de historiadores sobre la revolución han sido sugeridas por el Prof. Knight, en uno de los ensayos más conocidos en México (por su presentación en un Congreso de historiografía mexicanista y por su traducción al español, pero también uno de los más mal recibidos por los historiadores mexicanos; se trata del ensayo presentado en Oaxtepec en 1988 y publicado en Secuencia No. 13, enero-abril de 1989). Así, la primera generación sería la de los participantes (vgr. licenciados y generales revolucionarios, Vasconcelos y Obregón); la segunda, la de los primeros escritores profesionales que de alguna manera crearon la ortodoxia revolucionaria, pero que también supieron iniciar su crítica (como Cosío Villegas y Silva Herzog), y finalmente, los claramente profesionalizados (vgr. Luis González, etc.), hasta llegar así a los primeros trabajos revisionistas.

A diferencia de la historiografía general de las revoluciones que sugerí en un principio, el revisionismo entró a México prácticamente con la profesionalización del oficio y de la enseñanza de la historia más allá de la UNAM y El Colegio de México (es decir, después del '68), lo cual le dió un carácter no sólo crítico frente a la vulgarización del discurso revolucionario (lo cual era saludable), sino que se transformó en la nueva ortodoxia (dado el carácter cuasi-profético del medio intelectual y universitario del país y, desde luego, a la crisis del Estado central mexicano que hay que distinguir de la crisis priísta), ortodoxia en fin que me parece fundamental "revisar" ("revisar al revisionismo"), labor en la que sin duda los trabajos pioneros del Prof. Knight (claramente desde los años ochenta) han sido una guía imprescindible.

Podría pensarse que por la separación de la historiografía en generaciones comparto la idea de que cada generación reescribe su historia; si bien esta clasificación es más por razones analíticas, existen desde luego rasgos teórico y metodológicos que permiten identificar a un grupo de historiadores. Lo que nos muestra esta pequeña ronda de generaciones es por lo menos la riqueza de perspectivas que no podemos ignorar. Sin embargo, lo que observamos en la actualidad sobre la historiografía de la revolución mexicana es prácticamente la aplanadora del revisionismo. De aquí que los trabajos del Prof. Knight, como dijera en un principio, contribuyan a reestablecer el equilibrio historiográfico y más aún entre los tiempos mexicanos. 
Así pues, el libro que aquí nos convoca, la más completa síntesis sobre el periodo armado de la revolución (dicho incluso por Romana Falcón, una historiadora que inició directamente el cuestionamiento al carácter "popular" de la revolución, a través del caso de San Luis Potosí), cumple abundantemente con su cometido: mostrar el carácter complejo (es decir, diferenciado), popular y agrario de la revolución mexicana, en donde lo popular es observado más por las formas de resistencia campesina. Si bien reconoce y describe la diversidad regional de la revolución, el autor logra combinarlo con frecuentes reflexiones que permiten regresar al bosque sin perderse, reflexiones que serían desarrolladas en sus ensayos de crítica histórica.

Por ello me parece pertinente reseñar también algunos de esos ensayos en los que el Prof. Knight muestra su trabajo crítico. Cabe señalar aquí que, dentro de la sociología del conocimiento, una obra adquiere mayor validez no sólo por el contenido histórico de la propuesta teórica utilizada (lo cual las diferentes generaciones e interpretaciones podrían cubrir) sino también por la capacidad del historiador de comprender y criticar las perspectivas de los demás historiadores que han trabajado sobre el mismo proceso. En este sentido, los ensayos de Knight, poco conocidos en general, me parece que forman parte fundamental de su obra sobre la revolución mexicana. Destaca, por ejemplo, su primera crítica a la revolución "minera" propuesta por François Xavier Guerra, al insistir en el carácter agrario o "serrrano" de la revolución (en Annales, Economies, Sociétés, Civilisations, Marzo-abril 1983; curiosamente el ensayo de Guerra se conoció en español, mas no la crítica de Knight); su cuestionamiento a las interpretaciones marxistas (principalmente de Córdova, Gilly, Cockroft e incluso Ramón Eduardo Ruiz) por el uso inadecuado de las construcciones teóricas que llegaron a obscurecer e incluso a negar el carácter revolucionario y burgués (en su sentido amplio, es decir, de conquista de libertades y derechos frente al antiguo régimen y no sólo en su interpretación clasista) de la revolución mexicana (este ensayo apareció originalmente en Bulletin of Latin American Research en el Vol.4, No.2, 1985, y fue traducido en Cuadernos Políticos; por las respuestas airadas, este ensayo cayó como un verdadero balde de agua fría para la solemnidad de los académicos mexicanos), su insistencia en fin, en el carácter popular y agrario, no tan nacionalista, de la revolución frente a la actual moda revisionista de negarle estas características a la revolución.

Y digo moda porque hasta en los mejores historiadores ocurrió el proceso: 
vgr. John Womack, cuyo Zapata sin duda constituye una excelente argumentación a favor del carácter popular de la revolución, cambia su percepción y escribe una desencantada síntesis sobre la revolución mexicana para la Historia de Cambridge sobre América Latina. Peor aún, basta con ir a algún congreso de historia para escuchar la ortodoxia revisionista: la revolución, se dice, no cambió nada, cuando el sujeto de análisis es un municipio de Guanajuato y se observan sólo algunos años del periodo armado. Porque como lo ha sugerido el Prof. Knight, para apreciar en todas sus dimensiones a este proceso, habría que comenzar por cambiar la periodización: de 1880 a 1940 por ejemplo, ello bajo una perspectiva que nos permita contextualizar históricamente.

Se le ha criticado a Knight que vino a restablecer la vieja ortodoxia revolucionaria, como si ello significara automáticamente la legitimación del régimen surgido de la revolución (recuérdese la airada crítica de Alicia Hernández en el Congreso de Oaxtepec, historiadora que reeditara la historia whig el buen gobierno republicano). Sin embargo, mucho cuidado ha tenido el autor para no caer en la interpretación whig de la historia mexicana que, desde una perspectiva teleológica, termina justificando el presente. Para ello, es indispensable conocer su ensayo "Armas y Arcos en el Paisaje Revolucionario Mexicano" ("Weapons and Arches in the Mexican Revolutionary Landscape" en Everyday Forms of State Formation. Revolution and the Negotiation of Rule in Modern Mexico, Ed. por Gilbert M. Joseph y Daniel Nugent, Duke University Press, 1994), en donde Knight retoma a James C. Scott para analizar las formas de resistencia campesina en México (señalando, por ejemplo, que las políticas agrarias de los años treintas fueron la continuación de la guerrilla por otros medios), y lo combina con "el gran arco" propuesto por Corrigan y Sayer para analizar las transformaciones culturales que el estado posrevolucinario trajo consigo: una mayor homogeneización social y nacional; la quiebra de los particularismos regionales; en fin, la erosión del poder de la Iglesia y de las oligarquías... Porque el Estado surgido de la revolución, una obra de ingeniería cultural hoy ciertamente en crisis pero no por ello inexistente, es mucho más que la identificación con algún partido (lo cual nos lleva a revisar la idea en boga del Partido de Estado, en ocasiones añorada por los mismos prístas).

Se ha argumentado que en Aguascalientes el "verdadero" movimiento popular fue el de los cristeros, para seguir al revisionismo en uso. Sin embargo, como traté de mostrar en otra parte, hubo movimiento agrarios 
no necesariamente armados que, sin embargo, permitieron modificar las estructuras agrarias monopólicas del porfiriato hidrocálido, de tal forma que para mediados de los años treinta la estructura de la tenencia de la tierra y del agua se había transformado radicalmente. ¿Cómo fue posible este gran cambio en una sociedad pacífica y conservadora? La respuesta también la ha sugerido el Prof. Knight: más allá de las diferencias regionales, las transformaciones culturales que trajo consigo la consolidación del estado central permitió una mayor incorporación de las demandas campesinas, al punto de disminuir la fuerza de los hacendados y de la Iglesia. La pregunta entonces, se dirá, es qué tan favorables han sido los cambios introducidos por el estado nacional... Yo insistiría nuevamente en que la actual crisis nacional no debe impedirnos reconocer las transformaciones sociales posrevolucionarias, a riesgo de tirar el agua sucia con todo y niño.

Pero me parece que las preguntas están en otra parte, es decir, ¿por qué un historiador ha tenido que escribir más de 1,500 páginas para mostrar el carácter agrario y popular de la revolución mexicana? ¿Por qué la necesidad de una obra monumental, insisto en el monumentum como instrumento de la memoria, para recordarnos que efectivamente tuvimos un movimiento auténtico, con sus avances y retrocesos, con algunas continuidades pero también con grandes cambios? La respuesta quizá se encuentre no sólo en términos historiográficos, sino en nuestras fracturas históricas y sociales. Sin exagerar el argumento, pareciera que padecemos una neurosis colectiva como resultado de las encontradas percepciones sobre nuestro devenir histórico (es decir, nuestras percepciones sobre el pasado nos impiden reconocer el momento presente también como una oportunidad para el futuro).

Ciertamente la obra de Knight se coloca en la actual polémica sobre la revolución, polémica que muestra quizá la gran fractura existente en la sociedad mexicana y que requiere, así lo deseamos, una nueva integración, un nuevo pacto social; sin embargo, la obra de Knight también trasciende la polémica, es decir, se ubica en el "postrevisionismo" al proponernos una crítica histórica que permite reconciliarnos con nuestra historia, no para justificarla sino para comprenderla en su complejidad y, de esa manera, contribuir a descargar de nuestros hombros el peso del pasado. Más aún, como dijera Plumb, para contribuir a dar muerte a nuestro pasado (es decir, a las reconstrucciones ideologizadas del pasado), y de esa manera recomenzar a escribir nuestra historia. 